\title{
Recuperación de esquejes de Vanilla planifolia Andrews dañados por Fusarium oxysporum $f$. sp. vanillae
}

Recovery of cuttings from Vanilla planifolia Andrews damaged by Fusarium oxysporum f. sp. vanillae

Vargas Valencia Angélica ${ }^{1 凶 ;}$ Alarcón Pulido Sara Aída ${ }^{1}$; Vargas Zaleta Nimbe Eunice ${ }^{1}$; Montero Solís Flor María ${ }^{1}$ y Hernández Sánchez María de La Luz ${ }^{1}$.

${ }^{1}$ Facultad de Ciencias Biológico Agropecuarias. Universidad Veracruzana.

${ }^{\otimes}$ Autor para correspondencia: $\underline{\text { saalarcon@uv.mx }}$

Recibido: 05/08/2019

Aceptado: 13/12/2019

\section{RESUMEN}

Uno de los problemas que afecta los planes de cultivo y expansión de este cultivo en el mundo es su susceptibilidad a plagas y enfermedades. Fusarium oxysporum $f$. sp. vanillae como el principal agente causal más devastador y causante de la enfermedad de pudrición de tallo y raíz. A pesar de ser México centro de origen y domesticación de la vainilla actualmente no se cuentan con materiales genéticos resistentes a este patógeno, ni con métodos de control efectivos a esta enfermedad. Por tal razón se planteó la presente investigación con el objetivo de rescatar esquejes de Vanilla planifolia Andrews de un cultivo bajo malla sombra afectado por el hongo. El rescate de los esquejes de Vanilla planifolia Andrews atacada por el hongo Fusarium oxyporum vanillae consistió en la implementación de prácticas de manejo y aplicaciones de Fungicidas químicos, lo que en su conjunto contribuyó a que se recuperaran el $100 \%$ de los esquejes rescatados esperando que con los resultados de este estudio sirvan de base para el establecimiento de una guía técnica de manejo integrado del cultivo y apoyar a los productores para resolver la afectación del Fusarium que tan comúnmente se presenta en este cultivo.

Palabras clave: Vainilla, Fusarium oxysporum, Cultivo.

\begin{abstract}
ABSTRAC
One of the problems affecting the cultivation and expansion plans of this crop in the world is its susceptibility to pests and diseases. Fusarium oxysporum f. sp. vanilla as the most devastating and decoying main causal agent of stem and root rot disease. Despite being Mexico center of origin and domestication of vanilla, there are currently no genetic materials resistant to this pathogen, nor with
\end{abstract}


effective control methods to this disease. For this reason, this research was raised with the aim of rescuing Vanilla planifolia Andrews cuttings from a shady under-mesh crop affected by the fungus. The rescue of Vanilla planifolia Andrews cuttings attacked by the fungus Fusarium oxyporum vanillae consisted of the implementation of management practices and applications of Chemical Fungicides, which together contributed to the recovery of $100 \%$ of the rescued cuttings in the hope that the results of this study will serve as the basis for the establishment of an integrated crop management technical guide and support producers to resolve the affectation of Fusarium that is so commonly presented in this Culture.

Keywords: Vanilla, Fusarium oxysporum, Cultivation.

\section{INTRODUCCIÓN}

Las primeras referencias históricas acerca de la vainilla datan del siglo trece cuando el emperador azteca Itzcóatl (1427-1440) conquistó el territorio de la raza totonaca, denominado "Totonacapan", dentro del cual se encuentra la región vainillera, siendo obligados los totonacos a pagar tributos diversos, en entre ellos el fruto de la vainilla, llamado en mexicano "tlilxochitl" que significa flor negra. En totonaca se le denomina "zacanatanuxanath" que quiere decir vainilla madura y negra. El primer embarque de vainilla al viejo mundo fue hecho por Cortés en el año de 1519 cuando envió a España a Francisco de Montejo y a PortoCarrero, como portadores de los réditos de la conquista, consistentes en joyas, mantas y curiosidades entre las cuales se encontraba la vainilla. Aunque hay autores que aseguran que la vainilla fue llevada a Europa como perfume desde 1510 junto con cacao, índigo y cochinilla, diez años antes de la llegada del tabaco. Estos productos fueron llevados por veleros españoles que arribaron a México antes que Cortés.

Los conquistadores españoles llevaron la vainilla a su país y en el siglo XVI dominaban la comercialización de este producto a partir de la extracción y el cultivo en México. Desde España se dispersó a toda Europa, principalmente a los Jardines Botánicos donde se desarrollaron estudios sobre su horticultura (Peter, 2004). Posteriormente, la vainilla fue introducida a las colonias francesas, inglesas y holandesas a finales del siglo XVIII y principios del siglo XIX en sitios como Reunión, Java, India, Tahití y las islas Seychelles, entre otros.

Se estima que el mayor problema que enfrenta la producción de vainilla es la pudrición de la raíz ocasionada por el hongo Fusarium oxyporum Vanillae, que causa entre $30-52 \%$ de la muerte de las plantas, atacando las raíces adventicias e impidiendo así que la planta sea capaz de absorber agua y nutrientes. La aparición de Fusarium oxysporum f. sp. Vanillae (Fov) es favorecida por el exceso de sombra y las altas precipitaciones, así como los suelos degradados y la escasez de materia orgánica (Olivares, 2010).

Lo anterior originó que el cultivo se fuera reduciendo cada vez más, hasta casi desaparecer de su región de origen. Las plantaciones fueron descuidadas o abandonadas por los cosecheros al no tener garantías. En este sentido es importante hacer cumplir las disposiciones legales que reglamentan las operaciones de corte, beneficio, clasificación y comercialización de la vainilla, 
dedicándole al mismo tiempo personal agronómico para los efectos de una orientación y mejores rendimientos y de esta manera evitar la pérdida y conducir al rescate y aumento del área de siembra de esta orquídea en Veracruz. Veracruz es uno de los Estados de mayor importancia en cuanto a la producción de vainilla, en el estado de Veracruz las regiones productoras son: Papantla de Olarte, Martínez de la Torre, Gutiérrez Zamora, Tecolutla y Poza Rica de Hidalgo. En Puebla las zonas productoras son Cuetzalan del Progreso, Xochitlan de Romero Rubio, Ixtepec, Caxhuacán, estos dos estados aportan cerca del $80 \%$ de la producción nacional. En Oaxaca la principal zona productora de vainilla es Usila, región que en los últimos tres años (1998-2000) ha producido el $20 \%$ de la producción nacional de vainilla verde.

Durante los últimos años, se observó que los diversos indicadores de la producción de esta orquídea en México mejoraron de manera significativa, no así en el año 2000, en donde se registra no sólo una caída en los indicadores, sino también la desaparición del cultivo en la región totonaca de Puebla y el importante crecimiento de vainilla, en Oaxaca.

Para lograr lo anterior es necesario impulsar los sistemas de producción de vainilla compatibles con las condiciones físicas, socioeconómicas y culturales de la región. El objetivo del experimento fue Evaluar la recuperación de esquejes de Vanilla Planifolia Andrews dañados por Fusarium oxyporum vanillae provenientes de un sistema de cultivo de malla sombra.

El Fusarium oxysporum f. sp. Vanillae es una de las especies de mayor importancia fitopatológica, una de las que cuenta con mayor número de plantas hospedantes y una de las especies que mayor daño económico ocasiona entre los patógenos de plantas. La especie tiene la capacidad de atacar un gran número de plantas de importancia agrícola y ocasiona principalmente marchitamientos vasculares, seguidos de la muerte de la planta (Nelson, 1981). Algunas especies pueden ocasionar también pudrición de la corona y de las raíces de algunas plantas (Farr et al., 1989; Jones et al., 1997).

El hongo se caracteriza por producir colonias de crecimiento rápido y tres tipos de esporas: microconidias, macroconidias $\mathrm{y}$ clamidosporas.

Se estima que el mayor problema que enfrenta la producción de vainilla es la pudrición de la raíz ocasionada por el hongo $F$. oxyporum f. sp. Vanillae, que causa entre $30-52 \%$ de la muerte de las plantas, atacando las raíces adventicias e impidiendo así que la planta sea capaz de absorber agua y nutrientes. La aparición de $F$. oxysporum es favorecida por el exceso de sombra y las altas precipitaciones, así como los suelos degradados y la escasez de materia orgánica (Olivares, 2010).

Fusarium sp. es un hongo patógeno que se caracteriza por crecer formando colonias de diversos colores -blanco, rosado pálido, rojo, anaranjado, púrpura, celeste, verde aceituna- de manera moderada a rápida. El micelio de este hongo puede ser ralo o denso, algodonoso con funículos o limoso. Además, los pigmentos que difunden en el agar suelen variar de color o tono con el pH (Carrillo, 2003).

La relación de este hongo con la afectación en los cultivos de vainilla está dada por el efecto de la cepa Fusarium oxysporum f. sp. vanillae. La sintomatología se inicia con la aparición de lesiones de color café oscuro en los 
tallos de vainilla, junto con zonas cloróticas en los entrenudos, hasta que se produce la necrosis, reducción y muerte del tejido, que se traslada progresivamente del tallo al nudo (He, 2007). Por su parte, cuando el ataque del hongo se inicia en la raíz, el daño desciende a partir de las raíces adventicias. En condiciones de alta humedad, la pudrición es suave; la proliferación de micelio y conidios se presenta sobre el tejido dañado, agudizando el inóculo en la plantación (Bhai y Dhanesh, 2008).

La problemática principal alrededor del combate de $F$. oxysporum es que los fungicidas para el control de este hongo perturban el ciclo de interacción entre los hongos micorrizógenos nativos que integran la rizosfera de la vainilla, provocando una ocasional o casi nula reproducción por semilla en la naturaleza, y probablemente una disminución en la capacidad de absorción de nutrientes por las raíces adventicias (Gätjens y Montero, 2012).

\section{MATERIALES Y MÉTODOS}

El experimento se llevó a cabo en La Sierra de Otontepec localizada en la zona norte de la entidad Veracruzana, entre las coordenadas 97'58'30' y 9748'00', de longitud oeste, y $21^{\circ} 19^{\prime} 19^{\prime \prime}$ y 2109'34' de latitud norte aproximadamente, comprende una superficie de 15-152-00.00 hectáreas, donde incluye los Municipios de Cerro Azul, Citlaltépetl, Ixcatepec, Tepetzintla, Chontla, Tantima, Tancoco, y Chicontepec (SEDESMA 2007). Las variables de respuesta utilizadas fueron: Numero de hojas, Longitud de hojas, Numero y Longitud de brotes, Longitud de entrenudos, Numero de raíces aéreas, Longitud de planta y Número de plantas muertas. Para realizar la plantación se abrió al pie de cada tutor un surco de 5 a 10 centímetros de profundidad por 20 centímetros., de longitud y $8 \mathrm{~cm}$., de ancho Procurando que los nudos queden enterrados y el resto se dobla dándole una dirección hacia arriba sujetándolo por medio de un "jonote". Se seleccionaron al azar 35 plantas con síntomas de pudrición basal en plántulas de seis meses y plantas en pleno desarrollo, se aplicó 45g de Tecto 60 bombas de 20L, aplicación foliar cada 15 días, intercalando Bayfolan Forte $2 \mathrm{~g}$ x L de agua y Root Factor $2 \mathrm{~g}$ $x$ L de agua. La medición de las variables de respuesta se llevaron a cabo la primera quincena de octubre; 15 días después de la siembra, dejando pasar un lapso de 15 días entre cada medición haciendo un total de 7 mediciones entre los meses de Octubre a Enero a las diferentes variables, con excepción de la variable longitud de planta, la cual se inició a los 105 días de la primer medición, posterior al mes de diciembre en el que el capado natural de la planta disminuye considerablemente la longitud de esta. La cual se comenzó en el mes de febrero.

La longitud de los entrenudos fue mayor a los 105 días de la primera medición, es decir, el tamaño promedio más elevado del entrenudo fue en el mes de febrero, último mes registrado con promedio de $7 \mathrm{~cm}$ de diámetro del entrenudo. Como se aprecia en la Gráfica 1.

La tasa de crecimiento mayor se localiza en el mes de octubre 2018 con 15 días a finales de noviembre 2019 con 45 días transcurridos de la primera medición de $6.5 \mathrm{~cm}$ a $6.8 \mathrm{~cm}$. En los meses de diciembre y enero en los cuales el crecimiento se detuvo, con excepción de la última semana del mes de enero, en el cual comenzó la cúspide de los datos con $6.7 \mathrm{~cm}$ hasta $7 \mathrm{~cm}$. 


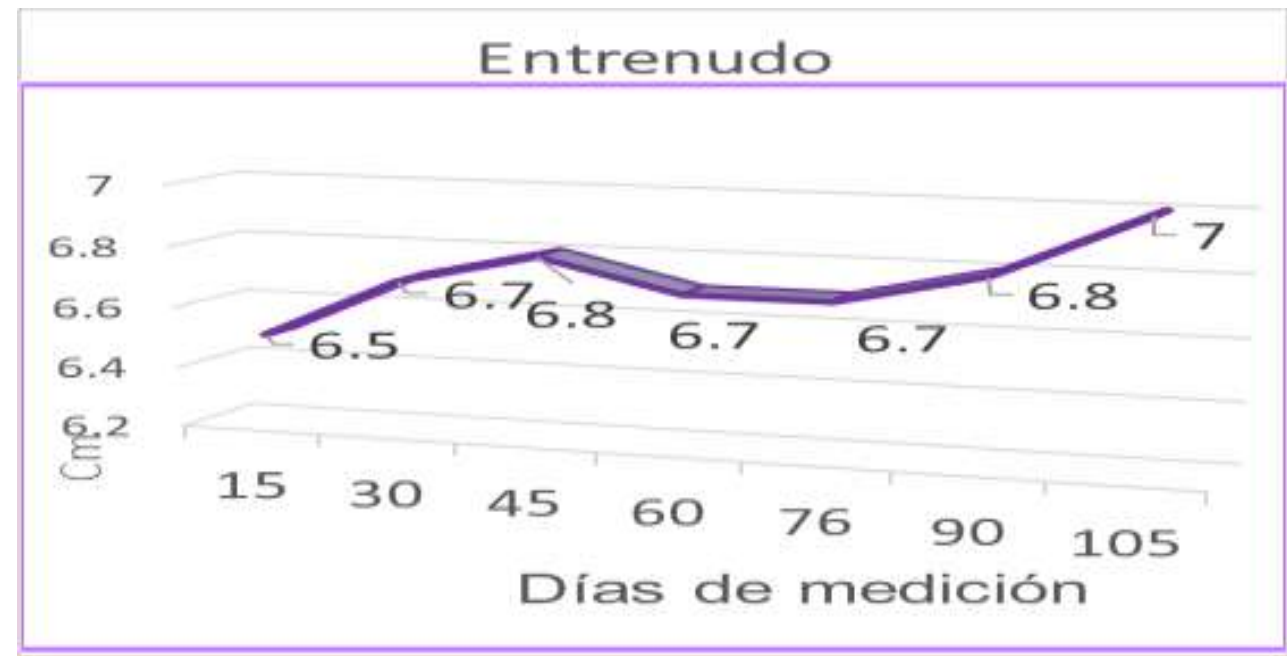

Gráfica 1. Longitud de entrenudos

La cúspide de número de hojas en las plantas seleccionadas fue en el mes de noviembre 2018 con 45 días tras el primer registro de datos, con un promedio de 17 hojas por planta. El número de hojas fue menor en los meses de diciembre a enero con 15 hojas por planta. La Vanilla planifolia, es una especie que prospera en clima tropical cálido húmedo y debido a las condiciones climáticas, es decir el frío retraso el crecimiento de la planta. (INIFAP). Respecto a la longitud, La vainilla presentó un crecimiento que supera los 30 metros de longitud, el tallo o bejuco, tenia aspecto carnoso, cilíndrico, poco ramificado, largo, flexible, formado por entrenudos de color verde oscuro de 10-15 cm. de longitud, lo que coincide con lo que señala Liahut, 1985.

El sistema radical de las plantas aumenta o disminuye en forma directamente proporcional, según el desarrollo de la parte aérea; de hecho, al intensificar la densidad de plantación en el intensivo de riego se reduce el tamaño de las plantas y, consecuentemente el sistema radical correspondiente. El sistema radical de las plantas de vainilla estudiadas fue de mayor población en el mes de noviembre con
45 días de la primera toma de datos, con un promedio de 7 raíces aéreas por planta.

Una vez analizados los resultados se observó una recuperación del 100\% de los esquejes contaminados por Fusarium oxysporum f. sp. vanillae. cuantificando el porcentaje de plantas muertas dentro del cultivo en acahual. Qué resulto en $0 \%$ así mismo destacando el rescate total de plantas evaluadas.

\section{LITERATURA CITADA}

Bacon, C. \& Hinton, D. (2007). Isolation in Planta Detection, and Uses of Endophytic Bacteria for Plant Protection. (pp. 638651). En C. Hurst. Manual of Environmental Microbiology. 3 ed. Santiago de Cali, Colombia. Bhai, S. https://doi.org/10.1128/9781555815882.ch Becerril A. Morales S. Tijerina C. Santizo J.2001. Crecimiento y desarrollo de vainilla en tres sistemas de producción en Papantla Ver. Re. Fitotec. Mex, Vol 24

Besse, P., D. Da Silva, S. Bory, M. Grisoni, F. Le Bellec, M.-F. Duval. 2004. RAPD genetic diversity in cultivated vanilla: Vanilla planifolia, and relationships with 
V. tahitensis and V. pompona. Plant Science 167: 379-385.

https://doi.org/10.1016/j.plantsci.2004.04

Bhai, S., J. Dhanesh, 2008. Occurrence of fungal diseases in vanilla (Vanilla planifolia Andrews) in Kerala. Journal of Spices and Aromatic Crops 17:140-148

Becerril A. Morales S. Tijerina C. Santizo J.2001. Crecimiento y desarrollo de vainilla en tres sistemas de producción en Papantla Ver. Re. Fitotec. Mex, Vol 24

Elorza Martínez, Pablo. 2010. Caracterización Fisiológica de la Vainilla (Vanilla Planifolia A.) Tesis de Doctorado. Universidad Autónoma del estado de Hidalgo. México.

Liahut, A.R.P. 1985. El sistema agroindustrial de vainilla vanilla planifolia Andr. En México. Universidad Autónoma de Chapingo, Méx, Tesis profesional. 84 P.
Ramírez-Mosqueda M.A., L. G. IglesiasAndreu*, J. C. Noa Carrazana, A. A. Armas-Silva. $2018 \quad$ Técnicas biotecnológicas para la obtención de genotipos de vanilla planifolia Jacks. Resistentes a fusarium oxysporum f. Sp. Vanillae. Cuadernos de Biodiversidad 54. https://doi.org/10.14198/cdbio.2018.54.02 Ramírez-Mosqueda M.A., Iglesias-Andreu L.G., Luna-Rodríguez, M. Castro-Luna A.A. 2015. In vitro phytotoxicity of culture filtrates of Fusarium oxysporum $\mathrm{f}$. sp. Vanillae in Vanilla planifolia Jacks. Scientia Horticulturae 197: 573-578 https://doi.org/10.1016/j.scienta.2015.10.0 19

Ranadive, A. S. 2005. Vanilla cultivation. P. 2532. In: Vanilla. Proceedings of the Firts International Congress, organized by the center for Flavor Education. Princeton, NJ, USA.

Copyright (c) 2019 Angélica V argas Valencia, Sara Aida Alarcón Pulido, Nimbe Eunice V argas Zaleta, Flor Maria Montero Solis y Maria de la Luz Hernández Sánchez

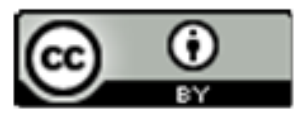

Este tex to está protegi do por una licencia licencia Creative Commons $\underline{4.0}$.

Usted es libre para Compartir — copiar y redistribuir el material en cualquier medio o form ato- y Adaptar el documento — remezclar, transformar y crear a partir del material- para cualquier propósito,, incluso para fines comerciales, siempre que cumpla la condición de:

Atribución: Usted debe dar crédito a la obra original de manera adecuada, proporcionar un enlace a la licencia, e indicar si se han realizado cam bios. Puede hacerlo en cualquier form a razonable, pero no de form a tal que sugiera que tiene el apoyo del licenciante o lo recibe por el uso que hace de la obra.

$\underline{\text { Resumendelicencia }}$ - Textocompletodelalicencia 